\title{
Evidências de pedogênese alóctone sobre arenitos Botucatu no sudoeste gaúcho
}

\author{
Evidences of allochtonous pedogenesis on sandstones in the Southwestern region of Rio Grande do Sul \\ Edgardo Ramos Medeiros', Fabrício de Araújo Pedron ${ }^{2}$ e Anderson Augusto Volpato Sccoti ${ }^{3}$ \\ 1,2,3. Universidade Federal de Santa Maria
}

\section{Resumo}

A região sudoeste do Rio Grande do Sul (RS) é caracterizada por grandes porções de solos arenosos que apresentam elevada fragilidade ambiental, devido a sua baixa fertilidade natural e alta suscetibilidade aos processos erosivos. Alguns destes solos apresentam incremento de argila, sugerindo pedogênese alóctone. Neste caso, objetivou-se determinar evidências de pedogênese alóctone sobre arenitos da Formação Botucatu na região sudoeste do RS. Foram analisados um perfil de Argissolo Vermelho e outro de Neossolo Quartzarênico, ambos formados sobre quartzo arenitos da formação Botucatu. Através de análises morfológicas, físicas, químicas e mineralógicas foi possível verificar o processo de pedogênese alóctone pela elevação no teor de argila no horizonte B do perfil de Argissolo e, pela ausência de minerais formadores de argila na rocha e presença de ilmenita nos horizontes pedogenéticos e sua ausência na rocha matriz. As condições ambientais sugerem que a ilmenita é originada da alteração de rochas vulcânicas circunvizinhas.

Palavras-chave: formação Botucatu, pedologia, solos arenosos, arenização, bioma Pampa

\begin{abstract}
The southwestern region of Rio Grande do Sul (RS) is characterized by large portions of sandy soils that have high environmental vulnerability, due to their low fertility and high susceptibility to erosion. Some of these soils have increased clay, suggesting allochtonous pedogenesis. In this case, the aims of this study were to determine evidence of allochtonous pedogenesis on sandstones Botucatu Formation in the southwestern region of the RS. A profile of Argissolo Vermelho and other of Neossolos Quartzarênico were analyzed, both formed on quartz sandstones of the Botucatu formation. Through morphological, physical, chemical and mineralogical analysis was possible to verify the process of allochthonous pedogenesis by higher clay content in the B horizon of the Argissolo profile and confirmed by the absence of clay forming minerals in the rock and in the presence of ilmenite in the pedogenetic horizons and its absence in the rock matrix. The environmental conditions suggest that the ilmenite originates from alteration of the surrounding volcanic rocks.
\end{abstract}

Keywords: pedology, sandy soils, desertification, Pampa ecosystem 


\section{INTRODUÇÃO}

A região sudoeste do Rio Grande do Sul (RS) ocupa uma área significativa do estado gaúcho e caracteriza-se pelo baixo desenvolvimento econômico, o que está associado as suas condições ecológicas e sociais. Localizada entre as latitudes $29^{\circ} 00^{\prime}$ e $31^{\circ} 00^{\prime} \mathrm{S}$ e as longitudes oeste $54^{\circ} 30^{\prime} \mathrm{e}$ $58^{\circ} 40^{\prime}$, esta região apresenta áreas arenosas, equivocadamente chamadas de desertos ou áreas de desertificação (Suertegaray, 1995). Estes areais são, na verdade, áreas naturais, que apresentam elevada fragilidade ambiental, sendo facilmente erodidas quando sob pressão antrópica (Medeiros et al. 1995).

O sudoeste gaúcho litologicamente é constituído por rochas vulcânicas e sedimentares as quais respondem de maneira diferente aos processos superficiais, determinando assim formas distintas de relevo e, por consequência, formas distintas de uso da terra. Estratigraficamente, a região é composta por rochas vulcânicas da Formação Serra Geral sobrepostas a rochas sedimentares continentais das Formações Botucatu e Guará, ambas respectivamente de origem eólica e predominantemente fluvial do período Jurásico-Cretáceo, pertencentes aos depósitos continentais da Bacia do Paraná (Petri \& Fúlfaro 1983).

A Formação Botucatu é constituída de arenitos eólicos, depositados sob clima árido em grande parte da Bacia do Paraná. Pelo menos, regionalmente, caracterizam-se por uma mineralogia predominantemente quartzosa, classificados segundo Folk (1974) como quartzo arenitos, por vezes com presença de feldspatos. No RS, estes minerais estão associados às áreas de areais e a solos arenosos com elevada fragilidade, principalmente a erosão, tanto fluvial quanto eólica (Brasil, 1973).

Os solos predominantes na região sobre arenitos Botucatu são os Neossolos Quartzarênicos e os Argissolos Vermelhos e Vermelho-Amarelos (Brasil, 1973; Klamt \& Schneider, 1995; Azevedo \& Kaminski, 1995). Alguns trabalhos realizados na região sugerem que os Argissolos sobre arenitos na região sudoeste do RS são formados através da adição externa de material argiloso de origem basáltica (Klamt \& Schneider, 1995). O estudo de Michelon et al, (2010) sobre a pedogênese alóctone em perfis de solos derivados de sedimentos no RS, não indicou a ocorrência desse processo em perfis desenvolvidos e arenitos grosseiros, mesmo em perfis com mudança textural abrupta.

A busca por maior conhecimento sobre a dinâmica pedogenética dos solos formados sobre os arenitos Botucatu no sudoeste gaúcho é fundamental para um maior entendimento da distribuição dos solos na paisagem, amenizando a carência de mapas de solos no RS (Dalmolin et al., 2004), e da sua elevada fragilidade aos processos superficiais, o que está diretamente relacionado com a sua capacidade de uso. Neste contexto, o objetivo deste trabalho é determinar as evidências de pedogênese alóctone sobre arenitos da Formação Botucatu na região sudoeste do Rio Grande do Sul.

\section{Material e métodos}

O trabalho foi realizado a partir do estudo de dois perfis de rocha-solo, desenvolvidos sobre os arenitos da Formação Botucatu, no município de Alegrete, RS. A Formação Botucatu assentada, estratigraficamente, sobre a Formação Guará ou Caturrita e encontra-se sotoposta à Formação Serra Geral. Tem uma espessura que oscila entre os 60 e 100 metros (Scherer \& Lavina, 2005).

Os arenitos da Formação Botucatu, segundo Scherer \& Lavina (2005), apresentam coloração bege a esbranquiçada e natureza predominantemente eólica. Caracterizam-se pela granulometria grossa e média pouco selecionada, por vezes finas e com matriz argilosa. Apresentam mineralogia quartzosa com grãos subangulosos e com subordinação de feldspatos. Possuem estratificação cruzada-acanalada, plano-paralela e maciça.

O clima da região é do tipo subtropical úmido, com possibilidade de seca definida no verão. A temperatura média anual é de $18,6^{\circ} \mathrm{C}$ e a precipitação anual é de $1574 \mathrm{~mm}$ (Maluf, 2000). Os solos predominantes conforme Brasil (1973) e Streck et al. (2008) são os Argissolos Vermelhos e Vermelho-Amarelos e os Neossolos Quartzarênicos nos topos e encostas de coxilhas e solos hidromórficos como os Planossolos Háplicos e os Gleissolos Háplicos nas depressões do terreno.

A escolha dos perfis foi realizada com base na sua representatividade litológica, geomorfológica e pedológica (tabela 1). Todos os horizontes de solo e camadas saprolíticas e rochosas foram amostrados nos dois perfis e, neste trabalho, denominadas de camadas $\mathrm{Cr}, \mathrm{CrR}, \mathrm{RCr}$ e $\mathrm{R}$, conforme EMBRAPA (2006) e Pedron et al. (2010). Foram coletadas amostras deformadas de todos os horizontes e camadas, e indeformadas e orientadas no sentido vertical das camadas $\mathrm{Cr}, \mathrm{CrR}, \mathrm{RCr}$ e R, com um formato aproximadamente cúbico com cerca de $10 \mathrm{~cm}$ de lado e revestidos com parafina para preservação de suas características físicas originais. 
Tabela 1. Dados ambientais e taxonômicos dos perfis estudados

\begin{tabular}{|c|c|c|c|c|c|}
\hline Perfil & $\begin{array}{c}\text { Declividade } \\
(\%)\end{array}$ & $\begin{array}{c}\text { Posição } \\
\text { paisagem }\end{array}$ & $\begin{array}{l}\text { Altitude } \\
\text { (m) }\end{array}$ & $\begin{array}{c}\text { Classificação } \\
\text { taxonômica }\end{array}$ & Coordenadas \\
\hline $\begin{array}{l}\text { Arroio Miracatu } \\
\text { (AM) }\end{array}$ & 5 & Meia encosta & 100 & $\begin{array}{l}\text { Argissolo } \\
\text { Vermelho }\end{array}$ & $\begin{array}{l}9^{\circ} 35^{\prime} 17^{\prime \prime} \mathrm{S} \\
55^{\circ} 25^{\prime} 02^{\prime \prime} \mathrm{W}\end{array}$ \\
\hline $\begin{array}{l}\text { IFF Alegrete } \\
\text { (IFFA) }\end{array}$ & 5 & Topo & 120 & $\begin{array}{c}\text { Neossolo } \\
\text { Quartzarênico }\end{array}$ & $\begin{array}{l}20^{\circ} 43^{\prime} 46^{\prime \prime} \mathrm{S} \\
55^{\circ} 32^{\prime} 54^{\prime \prime} \mathrm{W}\end{array}$ \\
\hline
\end{tabular}

As análises físicas, químicas e mineralógicas/petrográficas foram realizadas visando à determinação da composição mineral, classificação petrográfica, macro e micromorfometria e textura superficial de grãos minerais contituintes.

As amostras foram secas ao ar e levemente destorroadas. A determinação granulométrica foi realizada segundo a ABNT-NBR-7181 de dezembro de 1984. A amostra foi destorroada e submetida à dispersão química com hexametafosfato de sódio a $4,79 \%$ e dispersão física em agitador vertical. Após a dispersão das amostras, a fração areia foi separada da amostra via peneiramento úmido e fracionada via peneiramento seco. A argila foi separada por sedimentação via pipetagem. A fração silte foi determinada pela diferença entre as frações areia e argila.

As amostras foram distribuídas nas seguintes classes granulométricas, conforme Wentworth (1922): areia muito grossa: 2 a $1 \mathrm{~mm}$; areia grossa: 1 a $0,5 \mathrm{~mm}$; areia media: 0,5 a $0,25 \mathrm{~mm}$; areia fina: 0,25 a $0,125 \mathrm{~mm}$; areia muito fina: 0,125 a 0,062 $\mathrm{mm}$; silte: 0,062 a $0,002 \mathrm{~mm}$; argila: $<0,002 \mathrm{~mm}$. As classes texturais atribuídas a cada horizonte e camada foram baseadas em Santos et al. (2005).

$\mathrm{Na}$ análise mineralógica/petrogrática, $\mathrm{o}$ grau de friabilidade do substrato rochoso e pelo grau de dificuldade no reconhecimento mineral foram aspectos que definiram os procedimentos e técnicas analíticas utilizadas.

As amostras indeformadas correspondentes ao substrato rochoso, especialmente ao saprolito e em virtude, da possibilidade de desagregação, foram impregnadas com resina Araldite GY 1109 e endurecedor HY 951 na proporção 10:1 e mais corante Azul de Ceres na proporção 3\%. Foram adicionados cerca de $5 \%$ de acetona para a redução da viscosidade da resina e melhor penetração nas amostras. Subsequentemente, as amostras ficaram $8 \mathrm{~h}$ sob pressão negativa em bomba de vácuo. Após, permaneceram na estufa por $24 \mathrm{~h}$, com temperatura de $50^{\circ} \mathrm{C}$ para secagem e eliminação da acetona. Posteriormente, foram laminadas e levadas à microscopia de luz transmitida para a determinação da constituição mineral e classificação petrográfica, deteminada com o auxílio de um microscópio petrográfico de polarização com 4 objetivas e uma ocular de 8x.

A constituição mineralógica dos horizontes pedogênicos, assim como das camadas correspondentes à rocha matriz e ao saprolito, representados por amostras deformadas, como também os aspectos morfométricos como o arredondamento e os aspectos texturais da superficie dos grãos, foram determinados a partir da análise individual das várias frações granulométricas que compõem cada horizonte. Para tanto, foi utilizado uma lupa binocular com zoom progressivo e aumento maior de 40x. Para maior enriquecimento das informações, uma das oculares tanto da lupa quanto do microscópio foi frequentemente substituída por uma ocular digital de alta resolução com o objetivo de registro fotográfico de aspectos mineralógicos e texturais importantes dos grãos. A morfometria foi estabelecida por comparação visual conforme escala proposta por Power (in: Sgarbi, 2007), enquanto que a seleção dos constituintes detrítico de rocha sedimentar foi baseada em Pettijohn et al. (1987).

A técnica de Microscopia Eletrônica por Varredura (MEV) (Goldstein et al., 1992) foi utilizada para facilitar a determinação de alguns minerais pesados, especialmente os opacos pelo uso de microscopia comum.

Foi realizada análise química total de 12 elementos extraídos com $\mathrm{HNO}_{3}+\mathrm{HCl}+\mathrm{HF}$ e determinados por espectrometria de emissão atômica com plasma indutivamente acoplado (ICP-OES). No entanto, foram utilizados somente os elementos $\mathrm{Si}, \mathrm{Al}, \mathrm{Fe}, \mathrm{Ti}, \mathrm{Mg}$ e $\mathrm{Mn}$ em razão da mineralogia que compõe as camadas rochosas e os horizontes pedogenéticos. Embora, o zircão e até mesmo a turmalina ocorram em alguns horizontes, a percentagem de zircônio e de boro (nas turmalinas) foram insuficientes para serem detectados na análise. Os demais elementos, principalmente $\mathrm{Ca}$, $\mathrm{K}$ e $\mathrm{P}$ não foram considerados em razão da possibilidade de ocorrerem valores anômalos oriundos de correção e adubação do solo, visto algumas áreas serem de antigas lavouras ou até mesmo lavouras 
atuais. As amostras para difração de raios X foram preparadas de acordo com (EMBRAPA 1997). A fração argila das amostras, saprólito e solo foram analisados em lâminas orientadas. As amostras de argila foram saturadas com $\mathrm{K}^{+}$e analisadas antes $\left(\mathrm{K}^{+}\right.$a temperatura ambiente) e após tratamentos térmicos $\left(\mathrm{K}^{+}\right.$a $\left.550^{\circ} \mathrm{C}\right)$, saturados com etileno glicol. $\mathrm{O}$ equipamento utilizado foi um difratomêtro de raios $\mathrm{X}$, operando com filtro de níquel. A velocidade de varredura é de $1,2^{\circ} 2 \Theta \mathrm{min}^{-1}$, faixa de varredura de $3^{\circ}$ a $45^{\circ} 2 \Theta$, com tensão de aceleração de $30 \mathrm{Kv}$ e corrente de $30 \mathrm{~mA}$.

Os perfis foram classificados, até o segundo nível categórico, no sistema brasileiro de classificação de solo (SiBCS) conforme EMBRAPA (2006).

\section{RESULTADOS}

\section{Granulometria}

$\mathrm{Na}$ tabela 2, onde aparecem os dados granulométricos dos perfis analisados, nota-se que ao longo de todo o perfil AM, dentro do intervalo areia, predominam as classes de areia média e areia fina, com significativas variações em termos percentuais, especialmente a primeira, motivada pelo aporte da fração silte/argila a partir do horizonte pedogênico BC. O teor de argila é de $7,45 \%$ na camada $\mathrm{RCr}$, atinge seu pico de alta no horizonte $\mathrm{Bt}_{2}$, com $46,50 \%$, diminui paulatinamente em direção ao topo do perfil e chega a $16,14 \%$ no horizonte A. A fração areia fina aparece de maneira subordinada e praticamente mantém-se constante em termos percentuais, desde o substrato rochoso até o horizonte pedogênico superior. As demais frações arenosas são muito pouco representativas. É Interessante notar a característica praticamente bimodal do intervalo areia nas duas camadas do substrato rochoso ( $\mathrm{RCr}$ e $\mathrm{Cr}$ ).

De acordo com a classificação de Santos et al. (2005), no perfil AM, a textura varia desde areia nas camadas $\mathrm{RCr}$ e $\mathrm{Cr}$ até argila arenosa nos horizontes $\mathrm{Bt}_{3}$ e $\mathrm{Bt}_{2}$ e findando no horizonte $\mathrm{A}$ como franco arenosa.

No perfil IFFA, as frações areia mais representativas são a areia média, a fina e a muito fina. A primeira é a única que, em termos gerais, mostra um declínio em direção ao topo do perfil. As outras duas oscilam, respectivamente, de valores $15,51 \%$ e $22,34 \%$ na base do substrato rochoso, a $21,21 \%$ no horizonte $\mathrm{C}_{1}$ e $23,68 \%$ no horizonte $\mathrm{C}_{2}$. A percentagem de argila que no substrato rochoso é de $13,18 \%$, o que lhe confere a característica textural

Tabela 2. Distribuição granulométrica dos perfis derivados do Arenito Botucatu.

\begin{tabular}{|c|c|c|c|c|c|c|c|c|c|}
\hline \multirow[b]{2}{*}{$\begin{array}{l}\text { Horizontes/ } \\
\text { camadas }\end{array}$} & \multirow[b]{2}{*}{$\begin{array}{l}\text { Profundidade } \\
\qquad(\mathrm{cm})\end{array}$} & \multicolumn{7}{|c|}{ Classes granulométricas $(\%)$} & \multirow[b]{2}{*}{$\begin{array}{l}\text { Classe } \\
\text { textural }\end{array}$} \\
\hline & & $\begin{array}{l}\text { Areia } \\
\text { muito } \\
\text { grossa }\end{array}$ & $\begin{array}{l}\text { Areia } \\
\text { grossa }\end{array}$ & $\begin{array}{l}\text { Areia } \\
\text { média }\end{array}$ & $\begin{array}{c}\text { Areia } \\
\text { fina }\end{array}$ & $\begin{array}{c}\text { Areia } \\
\text { muito } \\
\text { fina }\end{array}$ & Silte & Argila & \\
\hline \multicolumn{10}{|c|}{ Perfil Arroio Miracatu (AM) - Argissolo Vermelho } \\
\hline A & $0-20$ & 0,09 & 1,03 & 25,04 & 29,92 & 11,06 & 16,72 & 16,14 & $\mathrm{FrAr}^{*}$ \\
\hline $\mathrm{Bt}_{\mathrm{l}}$ & $20-55$ & 0,13 & 0,85 & 20,29 & 26,26 & 10,94 & 10,59 & 30,94 & $\mathrm{FrArgAr}$ \\
\hline $\mathrm{Bt}_{2}$ & $55-100$ & 0,37 & 0,65 & 12,46 & 20,72 & 9,18 & 10,12 & 46,50 & $\mathrm{ArgAr}$ \\
\hline $\mathrm{Bt}_{3}$ & $100-150$ & 0,18 & 0,59 & 16,20 & 21,20 & 9,46 & 11,98 & 40,37 & $\operatorname{ArgAr}$ \\
\hline$B C$ & $150-210$ & 0,31 & 0,82 & 18,65 & 23,85 & 9,11 & 11,15 & 36,11 & FrArgAr \\
\hline $\mathrm{Cr}$ & $210-240$ & 0,00 & 1,09 & 56,36 & 21,80 & $\mid \mathrm{I}, 8 \mathrm{I}$ & 2,02 & 6,91 & Areia \\
\hline $\mathrm{RCr}$ & $240-400$ & 0,03 & 8,21 & 48,58 & 23,36 & 9,76 & 2,60 & 7,45 & Areia \\
\hline \multicolumn{10}{|c|}{ Perfil Instituto Federal Farroupilha Alegrete (IFFA) - Neossolo Quartzarênico } \\
\hline A & $0-18$ & 0,00 & 0,20 & 29,09 & 19,12 & 20,75 & 19,24 & 11,59 & $\mathrm{ArFr}$ \\
\hline$c_{1}$ & $18-50$ & 0,00 & 0,24 & 36,95 & 25,21 & 23,02 & 5,47 & 9,10 & Areia \\
\hline $\mathrm{C}_{2}$ & $50-85$ & 0,00 & 0,20 & 35,44 & 23,58 & 23,68 & 6,89 & $|0,2|$ & $\mathrm{ArFr}$ \\
\hline $\mathrm{C}_{3}$ & $85-115$ & 0,57 & 0,30 & 36,29 & 24,48 & 22,07 & 6,58 & 9,70 & $\mathrm{ArFr}$ \\
\hline $\mathrm{Cr}$ & $115-130$ & 0,12 & 0,17 & 44,77 & 18,36 & 17,27 & 5,61 & 13,68 & $\mathrm{ArFr}$ \\
\hline $\mathrm{R}$ & $130-200$ & 0,00 & 0,18 & 44,66 & $|5,5|$ & 22,34 & 4,25 & 13,18 & $\mathrm{ArFr}$ \\
\hline
\end{tabular}

*FrAr: Franco Arenoso; FrArgAr: Franco Argilo Arenoso; ArgAr: Argilo Arenoso; ArFr: Areia Franca. 
de areia franca, diminui em direção aos horizontes pedogênicos, passando no horizonte $\mathrm{C}_{1}$ à textura areia e voltando à areia franca no horizonte $\mathrm{A}$, quando atinge pouco mais de $11 \%$.

\section{Mineralogia e classificação petrográfica}

O substrato rochoso, formado pelas camadas $\mathrm{RCr}$ e $\mathrm{R}$, nos perfis AM e IFFA, respectivamente, constitui uma rocha sedimentar clástica que mostra uma laminação aproximadamente definida quando vista ao microscópio, com bandas de areia média intercaladas com bandas de areia fina a muito fina (Figura 1). Os clastos da fração areia muito fina, além de se posicionarem em lâminas, por vezes, ocupam espaço entre grãos maiores, comportando-se como matriz. Em uma mesma lâminação, a rocha pode ser considerada muito bem a moderadamente selecionada, porém, quando vista como um todo, mostra-se menos selecionada e assume quase um caráter bimodal, comum em sedimentos eólicos.

Os grãos são constituídos, na sua quase totalidade, por quartzo monocristalino que em geral se apresenta pouco fraturado, reconhecidos microscopicamente pela ausência de clivagem, baixa birrefringência, por vezes extinção ondulante e por apresentar, quando em luz convergente, características uniáxicas positivas. Completam a mineralogia, pesados como a magnetita titanífera (Figura 2), zircão e rutilo. A magnetita foi reconhecida por ser opaca e por apresentar hábito cúbico/octaédrico, tanto na microscopia de polarização quanto na microscopia de varredura. O zircão foi identificado pelo seu aspecto tetragonal, alto relevo, birrefringência elevada, extinção reta na microscopia de polarização e por sua característica composicional na microscopia de varredura. Já o rutilo foi reconhecido na microscopia de polarização pelo seu alto relevo e

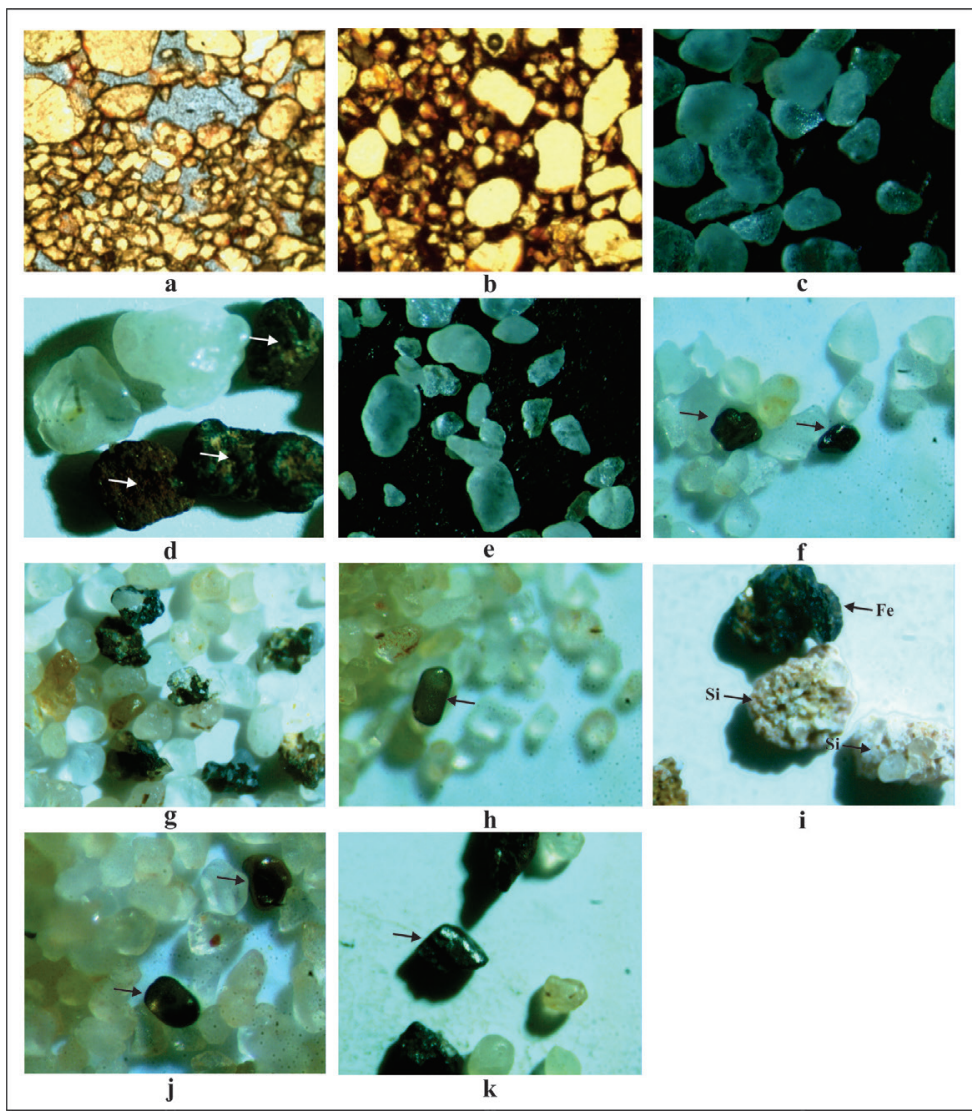

Figura 1. Imagens de microscopia de polarização e morfometria da fração areia dos perfis derivados do arenito Botucatu. a: estrutura laminada por variação granulométrica, camada RCr do perfil AM (microscopia de polarização LN - 80x); b: laminação por variação granulométrica, camada R do perfil IFFA (microscopia de polarização LN - 35x); c: retrabalhamento de clastos de quartzo, camada RCr do perfil AM (lupa 35x); d: agregados de quartzo cimentados por óxido de ferro, horizonte BC do perfil AM (lupa 40x); e: clastos arredondados na fração areia média e angulares na fração areia fina, horizonte BC do perfil AM (lupa 35x); f: clastos de zircão (esquerda) e rutilo (direita), camada R do perfil IFFA (lupa 35x); g: agregados de quartzo cimentados por óxido de ferro, camada Cr do perfil IFFA (lupa 35x); h: clasto de zircão, horizonte $\mathrm{C}_{3}$ do perfil IFFA (lupa 35x); i: agregados de quartzo cimentados por sílica (Si) e óxido de ferro ( $\mathrm{Fe}$ ), horizonte $\mathrm{C}_{3}$ do perfil IFFA (lupa 35x); j: clastos de zircão (abaixo) e de rutilo (acima), horizonte $\mathrm{C}_{2}$ (lupa $35 \mathrm{x}$ ); $\mathrm{k}$ : cristal cúbico de magnetita, horizonte A do perfil IFFA (lupa 35x). 
cor castanho avermelhada, levemente pleocróico em luz natural e por suas características composicionais no microscópio de varredura. Macroscopicamente, não foram identificados fragmentos de rochas. $\mathrm{Na}$ camada $\mathrm{RCr}$ do perfil IFFA, foram verificados raros fragmentos de feldspatos.

Alguns clastos apresentaram recobrimento parcial de uma fina película de material argiloso, identificada ao microscópio de polarização pela baixa birrefringência e por sua distribuição irregular entre os mesmos e identificada ao MEV por sua característica composicional e distribuição irregular sobre o grão. Da mesma maneira que argila, muitos clastos mostraram bordos e fraturas revestidos por óxido de ferro, esse reconhecido em luz natural (microscopia) por suas tintas de coloração averme- lhadas e macroscopicamente pelo aspecto vermelho amarelado que impõe aos clastos de quartzo.

A camada $\mathrm{RCr}$, com características granulométricas praticamente bimodais, é constituída no intervalo areia pelas frações areia média e areia fina, subordinadamente, pelas frações areia muito fina e grossa. Quanto ao retrabalhamento, os clastos tenderam a ser mal trabalhados em direção aos de menor diâmetro, onde predominam os sub-angulares a angulares e arredondados na fração areia grossa.

Quanto à classificação petrográfica, a elevada presença do intervalo granulométrico areia, constituído predominantemente por quartzo, sem feldspatos e fragmentos de rochas, permite classificar a rocha do perfil AM, segundo Folk (1974), como quartzo arenito. No perfil IFFA, a presença, mesmo
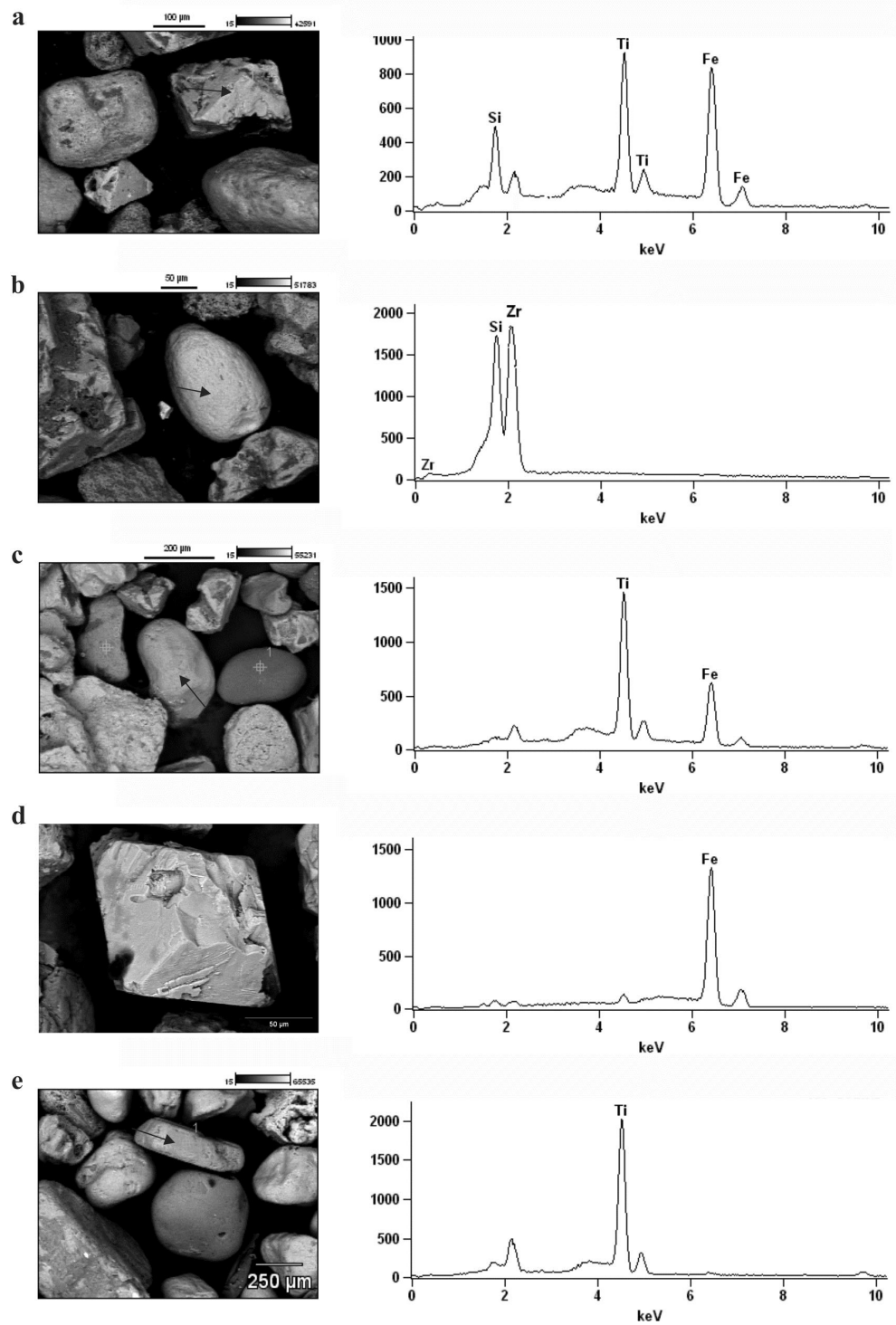

Figura 2. Fotomicrografias e gráficos composicionais obtidos pela microscopia eletrônica por varredura das amostras de rochas e saprolitos dos perfis desenvolvidos do arenito Botucatu. a: grão de magnetita titanífera, camada RCr do perfil AM; b: grão de zircão, camada RCr do perfil AM; c: grão de ilmenita, horizonte BC do perfil AM; d:grão de magnetita, camada R do perfil IFFA; e: grão de rutilo, camada $\mathrm{R}$ do perfil IFFA 
que rara de feldspatos faz com que o substrato rochoso possa ser enquadrado como um quartzo-arenito já na passagem para sub-arcósio. Nos dois perfis, trata-se de uma rocha mineralogicamente simples, com os clastos cimentados em geral por sílica e com elevada maturidade mineral.

\section{Mineralogia da areia e argila dos horizontes pedogenéticos}

Nos horizontes Bt1, Bt2 e Bt3 do perfil AM, a mineralogia da fração areia é constituída por quartzo, rutilo, magnetita e ilmenita. É relevante salientar que no horizonte $\mathrm{Bt} 2$ ocorre o menor teor da fração areia média $(12,46 \%)$, concomitante com o maior teor da fração argila (46,5\%). A mineralogia da fração argila é constituída por caulinita, hematita e quartzo com traços de mica (figura 3). No horizonte A, a fração areia torna-se mais representativa, perfazendo um total de quase $70 \%$. As frações areia média e areia fina mantêm-se como as mais significativas e a fração argila, idêntica aos horizontes $\mathrm{Bt}$, reduz-se a 16,14\%, fazendo com que a classificação textural do horizonte passe de franco argilo arenosa para franco arenosa. A mineralogia mantém-se quartzosa, tendo como acessórios o rutilo, a magnetita e a ilmenita. Acrescenta-se a ocorrência de psilomelano como no horizonte BC. No perfil IFFA, os horizontes C1, C2 e C3 apresentaram mineralogia da fração areia constituída

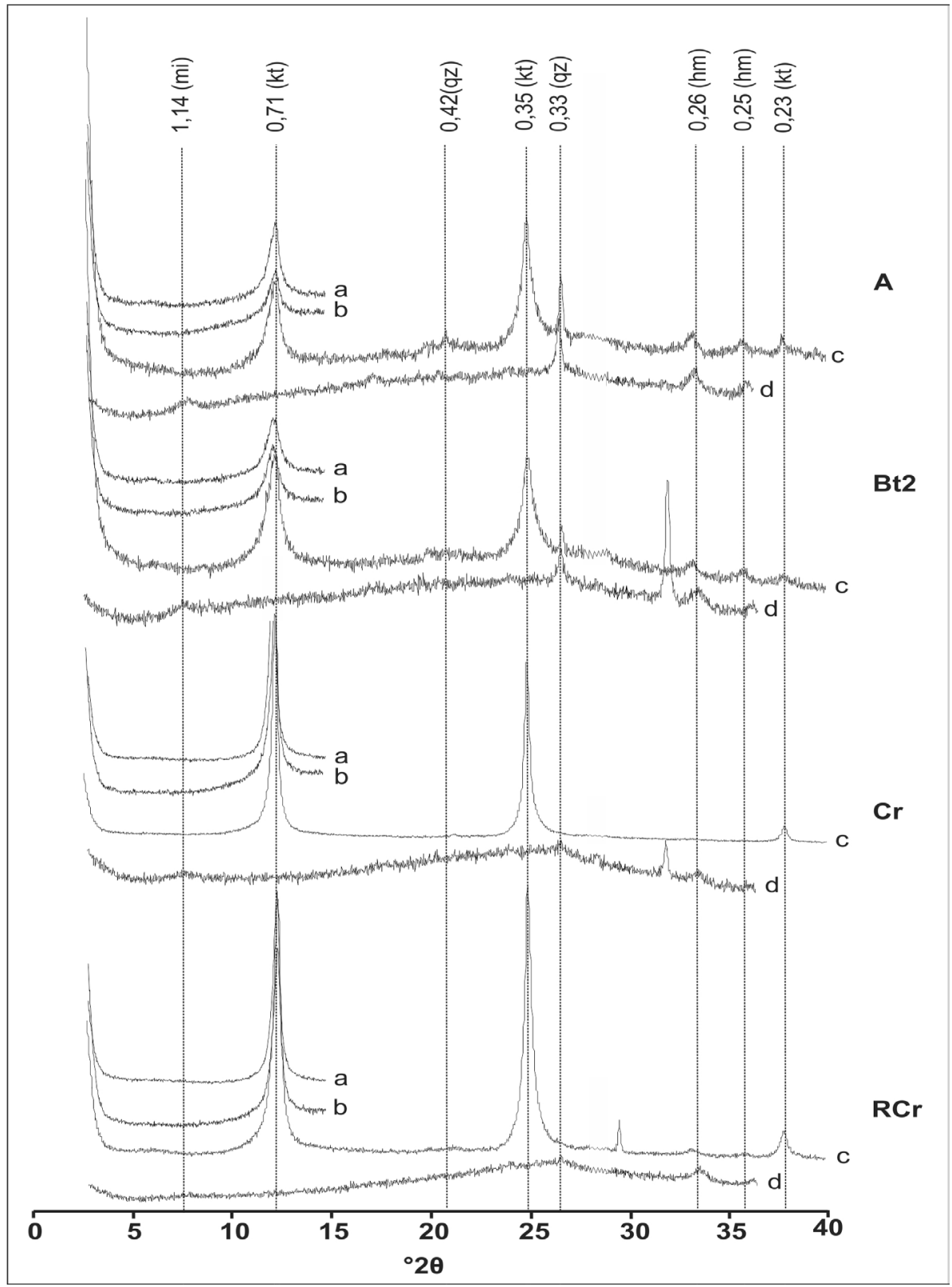

Figura 3. Raios X da fração argila no perfil AM. a=argila tratada com Mg a 25; b=argila tratada com $\mathrm{Mg}+$ etileno glicol; c=argila tratada com $\mathrm{K}$ a $25^{\circ} \mathrm{C} ; \mathrm{d}=$ argila tratada $\operatorname{com~} \mathrm{K}$ e aquecida a $550^{\circ} . \mathrm{mi}=$ mica; $\mathrm{Kt}=$ caulinita; qz= quartzo; $\mathrm{hm}=$ hematita. 
predominantemente por quartzo, com predomínio da textura fosca, tendo como minerais acessórios a magnetita, rutilo, zircão e ilmenita, estes com concentração na fração areia fina e muito fina (figura 1). A fração argila é constituída por caulinita e quartzo. A presença de argila 2:1 não foi confirmada no tratamento $\mathrm{Mg}+$ glicerol (figura 4). A presença de magnetita e de óxido de ferro cimentando agregados é frequente na fração areia grossa, embora essa seja pouco expressiva. Quanto ao retrabalhamento, os clastos das frações de maior diâmetro são em geral arredondados, tornando-se menos trabalhados em direção às frações areia fina e muito fina.

No horizonte A do IFFA, a mineralogia é constituída por quartzo e acessórios como o rutilo, zircão e muitos octaedros/cubos de magnetita, especialmente na fração areia muito fina. A magnetita foi reconhecida pelo hábito e pelo magnetismo. Acompanha, ainda dentro do intervalo, areia mineral opaco de ferro, reconhecido na lupa por suas tintas castanho avermelhadas como possível goethita. $\mathrm{Na}$ fração argila, foram identificados caulinita, quartzo, traços de hematita e mica. As frações granulométricas mais grosseiras mostram agregados de quartzo cimentados por óxido de ferro.

\section{Composição química dos perfis rocha-solo}

Na tabela 3, são apresentados os dados de dissolução química total para as amostras dos perfis

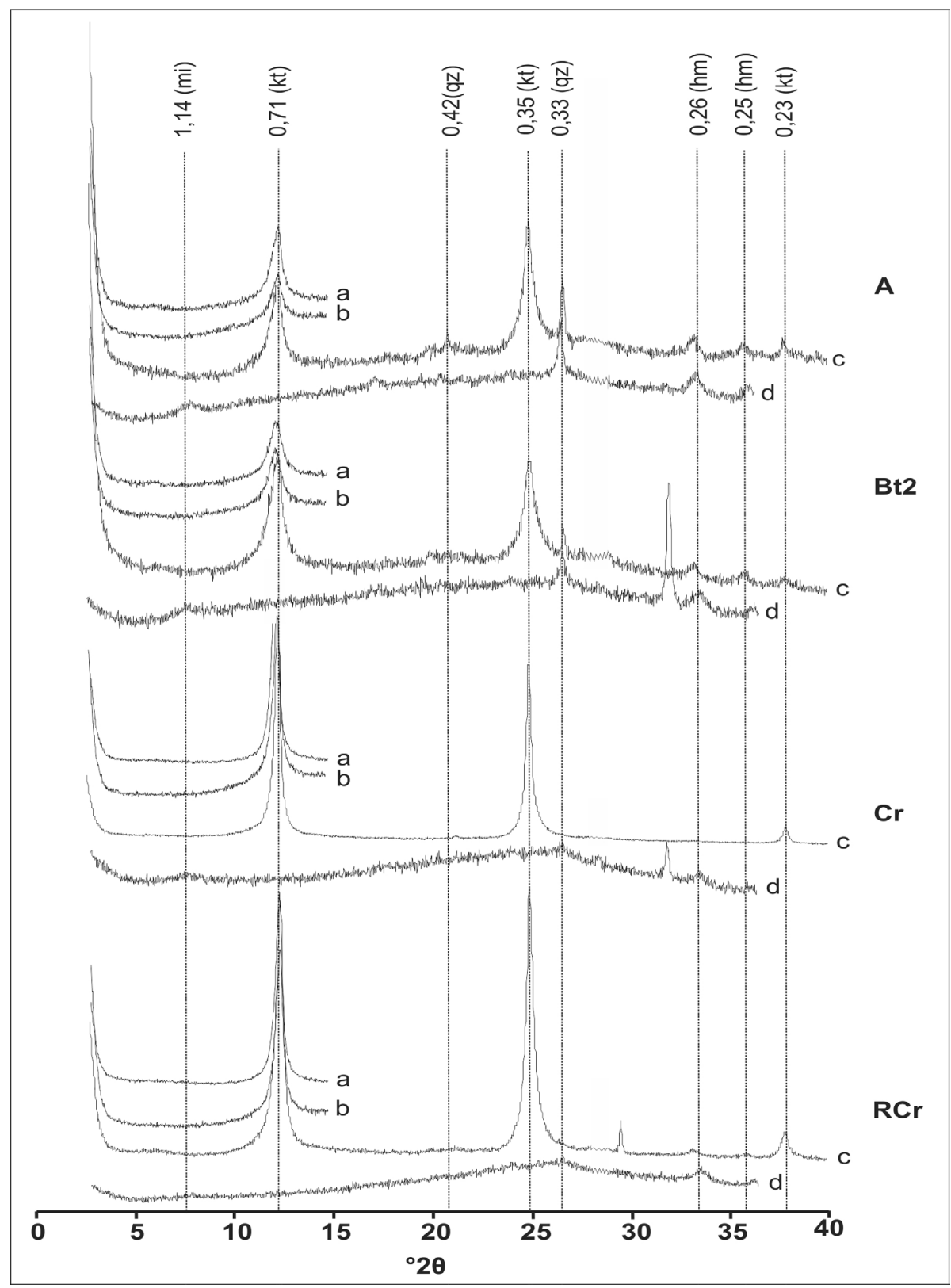

Figura 4. Raios X da fração argila no perfil IFFA. a=argila tratada com Mg a 25; b=argila tratada com Mg+etileno glicol; c=argila tratada com $\mathrm{K}$ a $25^{\circ} \mathrm{C}$; $\mathrm{d}=$ argila tratada com $\mathrm{K}$ e aquecida a $550^{\circ} . \mathrm{sm}=$ Esmectita; mi= mica; $\mathrm{Kt}=$ caulinita; $\mathrm{qz}=$ quartzo; $\mathrm{hm}=\mathrm{hematita}$. 
Tabela 3. Dados de dissolução química total das amostras dos perfis derivados do arenito Botucatu.

\begin{tabular}{|c|c|c|c|c|c|c|}
\hline \multirow{2}{*}{$\begin{array}{l}\text { Horizontes/ } \\
\text { camadas }\end{array}$} & $\mathrm{Si}$ & $\mathrm{Al}$ & $\mathrm{Fe}$ & $\mathrm{Ti}$ & $\mathrm{Mg}$ & $\mathrm{Mn}$ \\
\hline & \multicolumn{6}{|c|}{ - } \\
\hline \multicolumn{7}{|c|}{ Perfil Arroio Miracatu (AM) - Argissolo Vermelho } \\
\hline A & 468.642 & 23.418 & 19.845 & 4.209 & 2.058 & 337 \\
\hline $\mathrm{Bt}_{1}$ & 213.000 & 36.708 & 20.244 & 4.403 & 578 & 148 \\
\hline $\mathrm{Bt}_{2}$ & 198.000 & 58.451 & 30.702 & 5.835 & 811 & 177 \\
\hline $\mathrm{Bt}_{3}$ & 207.636 & 49.000 & 27.649 & 5.919 & 796 & 175 \\
\hline $\mathrm{BC}$ & 211.457 & 44.000 & 25.659 & 5.980 & 601 & 2.611 \\
\hline $\mathrm{Cr}$ & 448.086 & 11.000 & 2.969 & 517 & 98 & 11 \\
\hline $\mathrm{RCr}$ & 219.397 & 12.000 & 3.701 & 446 & 87 & 62 \\
\hline \multicolumn{7}{|c|}{ Perfil Instituto Federal Farroupilha Alegrete (IFFA) - Neossolo Quartzarênico } \\
\hline A & 377.720 & 16.000 & 27.745 & 909 & 2.842 & 544 \\
\hline $\mathrm{C}_{1}$ & 444.789 & 11.000 & 8.526 & 904 & 337 & 150 \\
\hline $\mathrm{C}_{2}$ & 292.000 & 9.999 & 8.565 & 2.845 & 325 & 132 \\
\hline $\mathrm{C}_{3}$ & 292.000 & 10.526 & 10.964 & 2.729 & 300 & 118 \\
\hline $\mathrm{Cr}$ & 288.000 & 19.646 & 8.350 & 1.133 & 641 & 54 \\
\hline $\mathrm{R}$ & 294.000 & 15.655 & 5.402 & 882 & 755 & 209 \\
\hline
\end{tabular}

derivados do Botucatu. No perfil AM, verifica-se que o silício, elemento mais abundante, tem dois picos de alta: um na camada $\mathrm{Cr}$ e outro no horizonte A. Já o titânio, a partir dos horizontes pedogênicos, mostra elevada concentração, sobremaneira nos horizontes $\mathrm{BC}, \mathrm{Bt}_{3}$ e $\mathrm{Bt}_{2}$, diminuindo em direção ao topo do perfil.

O alumínio e o ferro, em termos de concentração, acompanham proporcionalmente a elevação do titânio ao longo dos mesmos horizontes. Embora o mesmo aconteça com o magnésio, esse mostra um pico de alta no horizonte A, possivelmente vinculado, em parte, a procedimentos de correção de $\mathrm{pH}$ do solo, visto o quadro químico/ mineral não justificar tal crescimento anômalo. $\mathrm{O}$ manganês inicia, tal como o magnésio, baixo no substrato rochoso e mostra dois picos de alta, um no horizonte BC e outro no A. Em suma, os cinco elementos considerados, praticamente, apresentam as maiores concentrações nos mesmos horizontes intermediários, o que é refletida na mineralogia presente tanto nos acessórios das frações areia fina e muito fina quanto na fração argila.

No perfil IFFA, o teor de silício apesar de manter-se aproximadamente constante, mostra um pico de alta no horizonte $\mathrm{C}_{1}$. O quadro químico/ mineralógico, pelo menos aparentemente, não justifica tal crescimento. Já o alumínio, o ferro e em parte o titânio, quando comparados com o Perfil Arroio Miracatu, mostram-se, especialmente os dois primeiros, com concentrações significativas no substrato rochoso. Tanto o magnésio quanto o manganês mostram-se razoavelmente concentrados no substrato rochoso. Diminuem em direção ao meio do perfil e retomam com dois picos de alta no horizonte A. Esta elevação do teor de magnésio talvez esteja vinculada, pelos menos em parte, com processos de correção de $\mathrm{pH}$ do solo com a utilização de mármores dolomíticos moídos.

\section{DISCUSSÃO}

Embora os dois perfis tenham sido abertos sobre arenitos da Formação Botucatu, o substrato rochoso de ambos mostra, em termos proporcionais, uma relativa diferença em seus respectivos teores de argila. No AM, o teor de argila na rocha é de $7,45 \%$, já no IFFA, esse valor é de $13,18 \%$, que faz com que a classificação textural varie de areia no 
primeiro, para areia franca no segundo.

Em termos de classificação petrográfica, ambos são classificados, segundo Folk (1974), como quartzo-arenito, sendo que o Perfil IFF Alegrete já se encontra no limite para sub-arcósio em função do leve decréscimo no teor de quartzo e da presença, embora rara, de feldspato alterado, que associados ao aumento no teor de argila, impõem esta tendência. Essa variação do teor de argila entre os dois substratos rochosos tem respaldo tanto químico quanto mineralógico. Assim, a concentração de alumínio, que no Perfil AM oscilou entre 11.000 e $12.000 \mathrm{ug} \mathrm{g}^{-1}$, no IFFA variou entre $15.000 \mathrm{e}$ $19.646 \mathrm{ug} \mathrm{g}^{-1}$. Tal concentração é justificada pela presença de caulinita em ambos perfis, mas com valor mais alto no segundo em função da também ocorrência de argila $2: 1$, possivelmente esmectita, que é ausente no primeiro.

Os teores de Fe e Ti também diferiram entre os dois perfis, sendo praticamente o dobro no perfil IFFA. Tal variação está relacionada com a maior ocorrência de magnetita/magnetita titanífera e rutilo no Perfil IFFA. As variações das concentrações de magnésio e manganês estão, em principio, diretamente vinculadas à capacidade de substituírem o ferro ferroso na estrutura da magnetita. Já a presença de zircão, que é um mineral acessório constante em ambos substratos rochosos, não mostra variações significativas entre os mesmos.

Nos horizontes pedogênicos, os dois perfis passam a mostrar diferenças significativas tanto na distribuição granulométrica, sobretudo na fração argila, quanto na concentração dos elementos químicos principais que se refletem muito pouco em termos de variedade mineral e muito mais no teor de ocorrência dos mesmos. Assim, no Perfil AM, na passagem do substrato rochoso para os horizontes pedogênicos, ocorre um acréscimo expressivo da fração argila, que passa de cerca de $7 \%$ na camada Cr para $36 \%$ no horizonte $\mathrm{BC}$, atingindo o valor de $46 \%$ no horizonte $\mathrm{B}_{2}$, diminuindo em direção ao topo do perfil, quando passa para $16 \%$.

Os dados de raios $\mathrm{x}$ indicam que a fração argila é constituída por caulinita, quartzo e hematita, o que por si só já justifica as elevações das concentrações de alumínio e ferro que passam, respectivamente, de $11.000 \mathrm{ug} \mathrm{g}^{-1}$ e $2.969 \mathrm{ug} \mathrm{g}^{-1}$ na camada Cr para 44.000 ug g $^{-1}$ e 25.659 ug g $^{-1}$ no horizonte $\mathrm{BC}$, atingindo o pico de máxima no horizonte $\mathrm{Bt}_{2}$ quando chegam a $58.451 \mathrm{ug} \mathrm{g}^{-1} \mathrm{e}$ 30.702 ug g $^{-1}$, respectivamente.

A elevação dos teores de Ti nos horizontes subsuperficiais nos dois perfis está associada ao aporte significativo de ilmenita nestes horizontes. O magnésio acompanha geoquimicamente o ferro ferroso, a que pode substituir de maneira isomórfica tanto na magnetita quanto na ilmenita. Contudo, os teores elevados no horizonte A parece ser anômalo e muito mais vinculado a processo antrópico de correção de $\mathrm{pH}$ de solo do que substituindo o ferro em estrutura mineral. Já o manganês, embora possa também substituir ao ferro ferroso na estrutura da magnetita e da ilmenita, no perfil AM, a elevação do Mn deve estar associada à presença de psilomelano $\left(\mathrm{Ba} \mathrm{M}^{2} \mathrm{Mn}_{8}^{4} \mathrm{O}_{16}(\mathrm{OH})_{4}\right.$ ), justamente nos horizontes BC e A. Segundo Krauskopf (1972), trata-se de um mineral supergênico, cujo o manganês é oriundo da decomposição de rochas pré-existentes, acompanhando geoquimicamente o ferro ferroso até antes de sua precipitação como óxido.

Estabelecendo-se uma correlação simples de um elemento químico com outro (Spiegel, 1974), a única correlação expressiva (forte positiva) foi entre o ferro e o titânio, com valor próximo a $1(0,98807$ - dados não mostrados), indicando que o crescimento da concentração de ambos está fortemente interligado. Esse duplo crescimento de concentração pode ser explicado pelo aporte de ilmenita $\left(\mathrm{FeTiO}_{3}\right)$ ao longo dos horizontes pedogênicos.

Assim, além da influência do substrato rochoso, evidenciada pela manutenção do quartzo que em geral preserva seus aspectos morfométricos e por seus minerais acessórios que se repetem ao longo de todos os horizontes pedogênicos sobrepostos, a significativa variação tanto no teor de argila quanto na concentração dos elementos químicos principais presentes, retratada num aumento significativo de argilo-minerais e da participação de minerais acessórios, bem como pelo surgimento de uma mineralogia alheia ao substrato rochoso (ilmenita e psilomelano), indicam a forte participação alóctone no desenvolvimento pedogênico no perfil AM, cujo o material, por questões de vínculo original, parece estar ligado à alteração das rochas vulcânicas básicas do entorno.

No perfil IFFA o desenvolvimento do horizonte pedogênico superficial A é marcado também pela participação alóctone significativa do entorno geológico. A passagem do horizonte $\mathrm{C}_{1}$ para o A é caracterizada, entre outras, pelo crescimento significativo de $5,47 \%$ para $19,24 \%$ da fração silte, bem como do teor de alumínio que passa de $11000 \mathrm{ug} \mathrm{g}^{-1}$ para $16000 \mathrm{ug} \mathrm{g}^{-1}$. Esse crescimento, possivelmente vinculado ao aumento da fração argila, constituída por caulinita, quartzo e traços de hematita, ainda acrescida de argila $2: 1$. Essa última deve ter sua origem atrelada à decomposição do plagioclásio cálcico das rochas básicas, num nível intempérico ainda de pouca remoção de sílica. 


\section{CONCLUSÕES}

O processo de pedogênese alóctone foi indicado pela elevação no teor de argila no horizonte $B$ do perfil de Argissolo e confirmada pela ausência de minerais formadores de argila na rocha e presença de ilmenita nos horizontes pedogenéticos e sua ausência na rocha matriz. As condições ambientais sugerem que a ilmenita é originada da alteração de rochas vulcânicas circunvizinhas.

\section{LITERATURA CITADA}

AZEVEDO, A. C. \& KAMINSKI, J. Considerações sobre os solos dos campos de areia no Rio Grande do Sul. Ciênc. Ambiente. 11:65-70, 1995.

BRASIL, Ministério da Agricultura. Divisão de Pesquisa Pedológica. Levantamento de reconhecimento dos solos do Rio Grande do Sul. Recife: DNPEA-MA, 1973. 431p. (Boletim Técnico $\mathrm{N}^{\circ} 30$ ).

DALMOLIN, R. S. D.; KLAMT, E.; PEDRON, F. de A.; AZEVEDO, A. C. Relação entre as características e o uso das informações de levantamentos de solos de diferentes escalas. Ciência Rural, Santa Maria, v. 34, p. 1479-1486, 2004.

DANA, J. D. Manual de Mineralogia. Livros Técnicos e Científicos Editora S.A., Rio de Janeiro, 1978. 642p.

DEER, W. A.; HOWIE, R. A. \& ZUSSMAN, $\mathrm{J}$. Minerais constituintes das rochas - uma introdução. Fundação Calouste Gulbenkian, Lisboa. 1966. 558p.

EMPRESA BRASILEIRA DE PESQUISA AGROPECUÁRIA - EMBRAPA. Centro Nacional de Pesquisa de Solos. Sistema brasileiro de classificação de solos. 2.ed. Rio de Janeiro, EMBRAPA, 2006. 306p.

FOLK, R. Petrology of sedimentary rocks. Austin/ Texas: Hemphill Publishing Co, 1974. 182p.

GASPARETTO, N.V.L. \& SANTOS, M.L. O Emprego de Minerais Pesados como Indicador de Proveniência da Cobertura Pedológica do Arenito Caiuá na Região Noroeste do Paraná. Porto Alegre. UFRGS/Instituto de Geociências. Pesquisas em Geociências 32(1): 63-67, 2005.
GOLDSTEIN, J. I.; NEWBURRY, D. E.; ECHLIN, P.; JOY, D. C.; ROMIG JR., A. D.; LYMAN, C. E.; FIORI, C.; LIFSHIN, E. Scanning electron microscopy and X-ray microanalysis. $2 \mathrm{ed}$. New York: Plenum Press, 1992. 820p.

KLAMT, E. \& SCHNEIDER, P. Solos suscetíveis à erosão eólica e hídrica na região da Campanha do Rio Grande do Sul. Ciênc. Ambiente. 11:70-80, 1995.

KRAUSKPF, K.B. Introdução à Geoquímica II. São Paulo: Polígono, Editora da USP, 1972. 311p.

MALUF, J. R. T. Nova classificação climática do Estado do Rio Grande do Sul. R. Bras. Agrometeorologia, 8:141-150, 2000.

MEDEIROS, E. R.; MÜLLER F ${ }^{\circ}$, I. L.; VEIGA, P. O Mesozóico no oeste do Rio Grande do Sul (São Francisco de Assis e Alegrete). Acta Geológica Leopoldensia. 29:49-60, 1989.

MEDEIROS, E. R.; ROBAINA, L. E. S.; CABRAL, I. L. L. Degradação ambiental na região CentroOeste do Rio Grande do Sul. Ciênc. Ambiente. 11:53-64, 1995.

MICHELON, C. R.; AZEVEDO, A. C.; PEDRON, F. de A.; DALMOLIN, R. S. D.; GONÇALVES, J. L. \& JESUS, S. L. Causes of morphological discontinuities in soils of Depressão Central, Rio Grande do Sul State, Brazil. Sci. Agric., 67:319-326, 2010.

MÜLLER F ${ }^{o}$, I. L. Notas para o estudo da Geomorfologia do Rio Grande do Sul, Brasil. Publicação Especial no 1. Santa Maria: Imprensa Universitária - UFSM. 1970. 39p.

PAULA, P. M. \& ROBAINA, L. E. S. Mapeamento de unidades geológicas-geomorfológicas da bacia do Arroio Lajeado Grande. Geociências. 22:175184, 2003.

PEDRON, F. de A.; FINK, J. R.; DALMOLIN, R. S. D. \& AZEVEDO, A. C. Morfologia dos contatos entre solo-saprolito-rocha em Neossolos derivados de arenitos da Formação Caturrita no Rio Grande do Sul. Rev. Bras. Ciênc. Solo, 34:1941-1950, 2010.

PETRI, S. \& FÚLFARO, V. J. Geologia do Brasil. São Paulo: T. A. Queiroz: Ed. Da Universidade de São Paulo, 1983. 631p. 
PETTIJOHN, F. J. Rocas Sedimentarias. Buenos Aires: Editorial Universitária, 1976. 731p.

PETTIJOHN, F. J. Persistence of heavy minerals and geology age. Journal of Geology, 49:610-625 1941.

SANTOS, R.D.; LEMOS, R.C.; DOS SANTOS, H.G.; KER, J.C. \& DOS ANJOS, L.H.C. Manual de descrição e coleta de solo no campo. 5.ed.

Viçosa, MG, Sociedade Brasileira de Ciência do Solo, 2005. 100p.

SCHERER, C. M. S. \& LAVINA, E. L.

Sedimentary cycles and facies architecture of aeolian-fluvial strata of the Upper Jurassic Guará Formation, southern Brazil. Sedimentology, v. 32 p.1323-1341. 2005.

SGARBI, N. C. C. Petrografia macroscópica das rochas ígneas, sedimentares e metamórficas. Belo Horizonte, Editora da UFMG, 2007. 557p.

SOUTO, J. P. Desertos uma ameaça? Estudo do Núcleo de Desertificação na Fronteira Sudoeste do RS. Secretaria da Agricultura do Estado do Rio Grande do Sul. Porto Alegre, RS. 1984. 172p.

STRECK, E. V.; KÄMPF, N.; DALMOLIN, R. S. D.; KLAMT, E.; NASCIMENTO, P. C.; GIASSON, E. \& PINTO, L. F. S. Solos do Rio Grande do Sul. Porto Alegre, Emater/RS, 2008. 222p.

SUGUIO, K. Introdução à Sedimentologia. São

Paulo: Ed. Edgard Blucher, 1973. 317p.

WENTWORTH, C.K. A scale of grade and class terms for clastic sediments. Journal of Geology, 30: 377-392. 1922. 